\title{
Socioeconomic status and deaths due to unintentional injury among children: A socio-spatial analysis in Taiwan
}

\author{
An-Kuo Chou, ${ }^{1,2}$ Duan-Rung Chen ${ }^{3,4}$ \\ ${ }^{1}$ Department of Pediatrics, National Taiwan University Hospital, Hsin-Chu Branch, Hsinchu; ${ }^{2}$ Institute of \\ Health Policy and Management, College of Public Health, National Taiwan University; ${ }^{3}$ Institute of Health \\ Behaviors and Community Sciences, College of Public Health, National Taiwan University; ${ }^{4}$ Public Health \\ Research Center, National Taiwan University, Taipei, Taiwan
}

\begin{abstract}
In Taiwan, unintentional injury is the leading cause of death among children $<10$ years old. Low socioeconomic status is a risk factor associated with a high prevalence of injuries and our study aimed to explore the geographic distribution of mortality due to unintentional injury in this age group assessing the association between this type of injury on the one hand and socioeconomic disadvantages and family structure on the other using cluster and spatial regression analyses. Using exploratory factor analysis, we
\end{abstract}

Correspondence: Duan-Rung Chen, Institute of Health Behaviors and Community Sciences, College of Public Health, National Taiwan University, Room 636, No. 17, Xu-Zhou Road, Taipei 100, Taiwan. Tel.: +886.2.33668066 - Fax: +886.2.23434200.

E-mail: duan@ntu.edu.tw

Key words: Child; Local Spatial Autocorrelation; Spatial analysis; Unintentional injury mortality; Taiwan.

See online Appendix for additional Figures.

Contributions: AKC, data collection and analysis and manuscript writing; DRC, study design, manuscript review and references search.

Conflict of interest: the authors declare no potential conflict of interest.

Funding: this work was supported by the Ministry of Science and Technology (105 -2410-H-002 -075-MY2) and the Innovation and Policy Center for Population Health and Sustainable Environment (Population Health Research Center, PHRC), College of Public Health, National Taiwan University, from the Featured Areas Research Center Program within the framework of the Higher Education Sprout Project by the Ministry of Education (MOE) in Taiwan (grant number NTU107L9003).

Conference presentation: part of this paper was presented at the Pediatric Academic Societies Meeting, May 6-9, 2017, San Francisco, USA.

Received for publication: 6 September 2018 .

Revision received: 24 November 2018

Accepted for publication: 24 November 2018.

(C) Copyright A-K. Chou, and D-R. Chen, 2019

Licensee PAGEPress, Italy

Geospatial Health 2019; 14:736

doi:10.4081/gh.2019.736 assembled nine socioeconomic variables into four composite factors including area-level poverty, family burden, family fragility and unemployment. We found significant spatial clusters of childhood deaths due to unintentional injury and identified three major causes of death involved, i.e. traffic accidents, drowning and suffocation. Significant associations were found between death due to unintentional injury and area-level social disadvantages including poverty, family fragility, family economic burden and unemployment, while controlling for spatial autocorrelation. Our conclusion is that socioeconomic disadvantages need to be addressed to reduce the number of deaths due to childhood unintentional injury.

\section{Introduction}

The Global Burden of Disease Study 2016, issued by the Institute for Health Metrics and Evaluation, University of Washington, Washington DC, USA in collaboration with the World Health Organization (WHO) accounted more than 3 million deaths to unintentional injury in 2015 with nearly $20 \%$ of them in children under the age of 15 . This amounts to $10 \%$ of the world's child mortality in 2015 excluding deaths related to perinatal insult (WHO, 2016). The 2015 crude injury mortality rate among children aged 0-9 years in Taiwan was 30.3 per 100,000 population and injuries had caused one-fourth of these deaths (Ministry of Health and Welfare, Taiwan, 2016). Between 2011 and 2015, the rate of mortality due to injury decreased from 10.2 to 8.8 per 100,000 populations; however, mortality due to injury varied greatly in different areas, from 1.4 to 108.5 per 100,000 populations in 2015 (Ministry of Health and Welfare, Taiwan, 2018).

Unintentional injury is the major cause of death among children worldwide and they are always externally caused, e.g., motor vehicle injury, suffocation, drowning or due to burns and falls. Physical and social environment can influence the injury rate. With regard to pedestrian injury, more years spent in the family residence and more hours/days spent in school decrease the risk of road traffic injuries (Donroe et al., 2008). In addition, high traffic volume and high density of curb parking increase the risk of injury (Roberts et al., 1995). Low socioeconomic status (SES) has proved to be a strong predictor of childhood mortality due to injury and many studies have identified various risk factors of this occurring, including family poverty (Roberts et al., 1996; Singh and Yu, 1996), family structure (Östberg, 1997; maternal education (Scholer et al., 1999; Blakely et al., 2003; Schnitzer and Ewigman, 2008), race and/or ethnic minority issues (Singh and Yu, 1996) and living in low-income communities (Durkin et al., 1994; Laing and Logan, 1999). 
Geographic inequalities in health are strongly attributable to variation in the underlying social and environmental condition in populations and disparities in social determinants of health among children have been well documented (Poulton et al., 2002; Cheng et al., 2009). Recently, child mortality due to injury in relation to inequalities associated with the geographical area of residence have acquired importance because there are contextual factors at the spatial level that can explain health outcomes regardless of individual factors. In the US, for example, children in the most deprived socioeconomic quintile of the counties have been shown to have a $69 \%$ higher rate of mortality due to unintentional injury than children in the least deprived socioeconomic quintile (Singh and Kogan, 2007). Community factors that influence unintentional injuries are mostly correlated with income and population density (Baker et al., 1987), degree of urbanization (Yang et al., 1997) as well as education and family structure (Cubbin et al., 2000). Data from Canada suggest that aboriginal ethnicity also is a risk factor in unintentional fall injury and this has multiple interactions with the number of people per room in the home and participation in the labour force instead of residence location (Jin et al., 2017) although the mechanism by which socioeconomic factors exert an effect on health are not always clear, poverty, low educational attainment and relative deprivation can increase the exposure to environmental hazards. However, when developing interventions aimed at reducing such inequalities, identification of patterns with respect to geographical areas with poor levels of health and other socio-economic indicators would better support outcomes than one-size-fits-all approaches.

Injury remains the leading cause of death among Taiwan children and the rate is higher than in most countries belonging to the Organization for Economic Co-operation and Development that includes Japan and Korea, countries with a similar cultural background to that of Taiwan (Liang et al., 2016). To date, however, no small-area analysis of child mortality due to unintentional injury in Taiwan has been published. Our study therefore aimed to identify township-level inequalities in child unintentional mortality due to injury using the national death statistic registry programme. We used spatial analysis to study patterns in the rates of age-adjusted child mortality due to injury at the level of townships and small cities invoking tests for the potential associations between mortality and place of residence, demography and socioeconomic characteristics.

\section{Materials and Methods}

\section{Mortality records}

Vital statistics on data mortality due to injury for the period 2000-2007 were obtained from the Ministry of Health and Welfare of Taiwan. All unintentional deaths among children age 0-9 years were included in the analysis using the classification of International Classification of Diseases, Ninth Revision (ICD-9) external-cause -of-injury codes (E800-E929), available from the US Center for Disease Control and Prevention (CDC), was used (CDC, 2013). The main causes in this cohort are classified according to the matrix of E-code groupings for mortality due to injury and morbidity data (CDC, 2011). The top 3 injury diagnoses in this cohort were motor vehicle-related injury (E810-E829) (28.9\%), suffocation (E911-E913) (22.0\%) and drowning (E830, E832, E910) $(21.6 \%)$.

\section{Socioeconomic variables}

As we were interested in a small-area analysis, we included all townships and small cities in Taiwan $(n=349)$. To characterize township-level socioeconomic conditions, we first identified information from Taiwan's census statistics depicting neighbourhood and household economic conditions. We included variables with known socioeconomic differences within townships, such as per capita income, education and employment as well as the SES of the households with respect to employment and marital status including family structure (single, two-parent or grandparent home). We excluded redundant variables by looking closely at how correlated they were. Two variables with Pearson correlation coefficients ranging from 0.8 to 1.0 were excluded from further analysis. This overall selection process resulted in nine township-level variables that differentiated the residences under study in a useful way (Table 1). Next, we analysed these variables using exploratory factor analysis for the principal component using varimax with Kaiser normalization method (Pearson, 1901). The level of KaiserMeyer-Olkin measure of sampling adequacy was 0.639 indicating a significant difference by the Bartlett sphericity test $(\mathrm{P} \leq 0.001)$ (Cerny et al., 1977). The pattern matrix of the four most important factors found are shown in Table 2 (together explaining $82.5 \%$ of the variance) with the variables contributing most to the formation of each factor (loading $>0.60$ ) in bold. Each factor emphasized var-

Table 1. Definition of the nine socioeconomic factors used in the study.

\begin{tabular}{|c|c|}
\hline Factor (type of expression) & Description \\
\hline Per capita income (\$) & Total income divided by the township population. \\
\hline Divorced with household headed by female (\%) & The divorced female household population divided by the total household population \\
\hline Single-parent household (\%) & The number of single-parent families divided by the total number of families \\
\hline Household headed by grandparent(s) (\%) & The number of grandparents rearing families divided by the total number of families \\
\hline Population without high-school degree (\%) & $\begin{array}{l}\text { The population above } 15 \text { years of age with elementary school education or lower, } \\
\text { divided by the total population above } 15\end{array}$ \\
\hline Employment in agriculture (\%) & The population with agricultural employment divided by the total population \\
\hline Household without income (\%) & The number of unemployed households divided by the total population \\
\hline Unemployed males (\%) & The number of unemployed males above 15 years old as a percentage of the male labour force \\
\hline Unemployed females (\%) & The number of unemployed females above 15 years old a percentage of the female labour force \\
\hline
\end{tabular}

Data source: Directorate-General of Budget, Accounting and Statics, Taiwan. 
ious types of regional disparity as follows: i) Township-level poverty underlining the socioeconomic disadvantages of residency; ii) family burden representing limited family resources/support and family difficulties; iii) family fragility reflecting a broken family structure that is either single-parent family or family led by grandparents; iv) variables representing the township-level employment rate.

\section{Cluster mapping}

The SPSS v. 20 software statistical software package (SPSS Inc., Chicago, IL, USA) was used to analyse the injury mortality data and factor analysis. The annual age-specific mortality rates per 100,000 were calculated for the period 2000-2007 using agespecific population data from the 2004 census as denominator and adjusted by age standardization of the population data (Ahmad et al., 2001). To reduce undue large variations resulting from the collection of data from regions with small populations, empirical Bayesian smoothing was applied to the computed raw rates (Clayton and Kaldor, 1987). To identify clustering in all-cause and specific-cause mortality rates, the local indicator of spatial autocorrelation (LISA) and Moran's I with an empirical Bayes smoother were applied. This approach was used to identify hotspots, i.e. areas with high rates surrounded by areas with high rates $(\mathrm{HH})$ and also cold spots, i.e. areas with low rate surrounded by areas with low rates (LL). Global Moran's I statistics was applied to measure spatial autocorrelations across the study. Negative (positive) values indicate negative (positive) spatial autocorrelation and values range from -1 (indicating perfect dispersion) to +1 (perfect correlation). Positive autocorrelation indicates that points with similar attribute values are closely distributed in space whereas negative spatial autocorrelation indicates that closely associated points are dissimilar. P-values $<0.05$ were considered significant and the number of permutations was set to 999 .

\section{Association between area-level socioeconomic status and child mortality}

To determine the association between SES and child mortality at due to unintentional injury the local level, we first employed ordinary least square (OLS) models and tested the residuals for spatial autocorrelation using Global Moran's I. Because Global Moran's $I$ values for the residuals were significant at $\mathrm{P} \leq 0.001$, it spatial lag regression modelling was used to explicitly test the relationship between SES and mortality with regard to injury while controlling for spatial clustering (Brunsdon et al., 1998). We used OpenGeoda 1.12.1 software (Center for Spatial Data Science, University of Chicago, IL, USA) to carry out all these geospatial analyses and producing choropleth maps in ArcGis 10.2 (ESRI, Redlands, CA, USA).

\section{Results}

For the period 2000-2007, a total of 2,377 children aged 0-9 years, who had died from unintentional injury, were identified. The average age-specific, annual mortality rate was 10.76 per 100,000 children. The minimum, annual township incidence rate was 0.0 and the maximum 147.92, which is quite an enormous difference. An illustration of the uneven distribution of these deaths across townships can be seen in Figure 1A, which presents the average annual mortality rate due to unintentional injury. The results of cluster analysis (Figure 1B) reinforce this impression. The Moran's $I$ of these accumulated deaths was 0.3794 , which has a high statistical significance $(\mathrm{P} \leq 0.01)$.

\section{Spatial clusters}

When the accumulated spatial clustering (Figure 1B) was instead presented on an annual basis (Appendix Figure A1), large variations of both hotspots and cold spots can be seen. Although the hotspots were not the same, they tended to overlap and commonly include the counties Nantou, Hualien and Hsinchu. Using the LISA approach to analyze the high mortality regions and neighbouring areas, we found $36 \mathrm{HH}$ regions located in the central mountains and eastern regions of Taiwan. The coldspots, a total of 43 LL regions, were primarily seen in the cities. The rate of deaths due to unintentional injury in the townships were thus correlated suggesting an underlying socioeconomic condition. For the youngest children, the clusters of deaths due to unintentional injury were statistically significant with the male subgroup (Figure 2A, C) showing spatial clusters in areas similar to those seen in the female subgroup. These findings were observed in central part of Taiwan. In the male group, the value of Moran's $I$ was 0.2781 $(\mathrm{P} \leq 0.01)$ and $26 \mathrm{HH}$ regions were identified with significant spatial clustering. In the female group, the value of Moran's $I$ was 0.2162 ( $\mathrm{P} \leq 0.01$ ), and $23 \mathrm{HH}$ regions were identified, also with significant spatial clustering. In the older children, only the male subgroup presented a spatial cluster (Moran's $I=0.1430, \mathrm{P} \leq 0.01$ ) with

Table 2. Pattern matrix from factor analysis.

\begin{tabular}{|c|c|c|c|c|}
\hline Factor (type of expression) & Regional poverty & Family burden & Family fragility & Regional unemployment \\
\hline Per capita income $(\$)$ & 0.902 & 0.036 & -0.066 & -0.159 \\
\hline Divorced, household headed by female (\%) & -0.535 & -0.085 & 0.778 & 0.047 \\
\hline Single-parent household (\%) & 0.201 & 0.164 & 0.931 & 0.061 \\
\hline Household headed by grandparent(s) (\%) & 0.440 & 0.728 & 0.036 & -0.033 \\
\hline Population without high-school degree (\%) & 0.864 & 0.380 & -0.119 & -0.077 \\
\hline Employment in agriculture (\%) & -0.881 & -0.003 & -0.090 & 0.028 \\
\hline Household without income (\%) & -0.052 & 0.913 & 0.079 & 0.088 \\
\hline Male unemployed population (\%) & 0.021 & -0.050 & 0.075 & 0.866 \\
\hline Female unemployed population (\%) & -0.203 & 0.117 & 0.005 & 0.810 \\
\hline Explained variability (\%) & 32.230 & 17.325 & 16.807 & 16.151 \\
\hline
\end{tabular}


$19 \mathrm{HH}$ regions (Figure 2B). The central mountains and eastern regions were again included in these areas. In the female group, there was no spatial cluster but $6 \mathrm{HH}$ regions were identified (Figure 2D).

\section{Role of traffic accidents}

Moran's $I$ of the rate of deaths due to traffic accidents between 2000 and 2007 was 0.189 with a statistical significance of $P \leq 0.05$. LISA analysis showed $20 \mathrm{HH}$ regions (Figure 3A). Age and gender factors were analysed and a spatial clustering found in the 0-4-year age group but not in the 5-9-year age group (Appendix Figure A2A-D).

\section{Role of drowning}

Moran's $I$ of the rate of death through drowning between 2000 and 2007 was 0.3391 , which indicates a statistical significance at $\mathrm{P} \leq 0.01$. LISA analysis showed $27 \mathrm{HH}$ regions (Figure 3B). Age and gender factors were analysed, and spatial clustering was found in the 0-4-year age group but not in the 5-9-year age group (Appendix Figure A2E-H).

\section{Role of suffocation}

Moran's $I$ of the rate of death through suffocation between 2000 and 2007 was 0.1164 , which indicates statistical significance and LISA analysis showed $13 \mathrm{HH}$ regions (Figure 3C). Age and gender factors were analysed and spatial clustering was found in the male group aged 0-4 years and in the female group aged 5-9 years (Appendix Figure A2I-L).

\section{Township-level socioeconomic status components}

The township-level poverty component showed a very strong spatial clustering and the value of Moran's $I$ was $0.7400(\mathrm{P} \leq 0.01)$ (Figure 4A). Moran's $I$ of family burden component was 0.4304 $(\mathrm{P} \leq 0.01)$ and LISA analysis showed HH areas located in the Northeast and on the eastern coast of the island (Figure 4B). Moran's $I$ of family fragility component was $0.5621(\mathrm{P} \leq 0.01)$ and the $\mathrm{HH}$ areas concentrated in the East, the south-eastern coast and the central part of island (Figure 4C). It was not any spatial clustering with regard to regional unemployment and Moran's $I$ was 0.0529 $(\mathrm{P} \geq 0.05)$ (Figure 4D).

\section{Regression analysis}

Four SES components (regional poverty, family fragility, family burden and regional unemployment) were found to be significantly related to death due to unintentional injury (Table 2). The most significant factor was township-level poverty (beta coefficient $=0.419$ ). However, Moran's $I$ of the residuals was 0.2304 $(\mathrm{P} \leq 0.01)$ suggesting that further spatial lag model is warranted due to the effect of spatial autocorrelation. An analysis of all deaths due to unintentional injury by the spatial lag model, the four components remained significant but the beta coefficient decreased and the spatial autocorrelation Rho $(\rho)$ was 0.377 (statistically significant at $\mathrm{P} \leq 0.01$ ), while $\mathrm{R}^{2}$ ranged from 0.285 to 0.375 indicating that these deaths were associated with spatial neighbouring effects For deaths due to traffic accidents, poverty rate and family fragility were the significant factors (Table 2). Moran's $I$ of the residuals was $0.0917(\mathrm{P} \leq 0.01)$, while the spatial lag model showed a Rho of


Figure 1. Average rate of annual mortality due to unintentional injury among children age 0-9 years across 349 regions (townships and cities) in Taiwan during 2000-2007. (A) Mortality rate per 100,000 population; (B) Cluster graph showing hotspots (red) and cold spots (blue). $\mathrm{HH}$, high rates; $\mathrm{LL}$, low rates. 

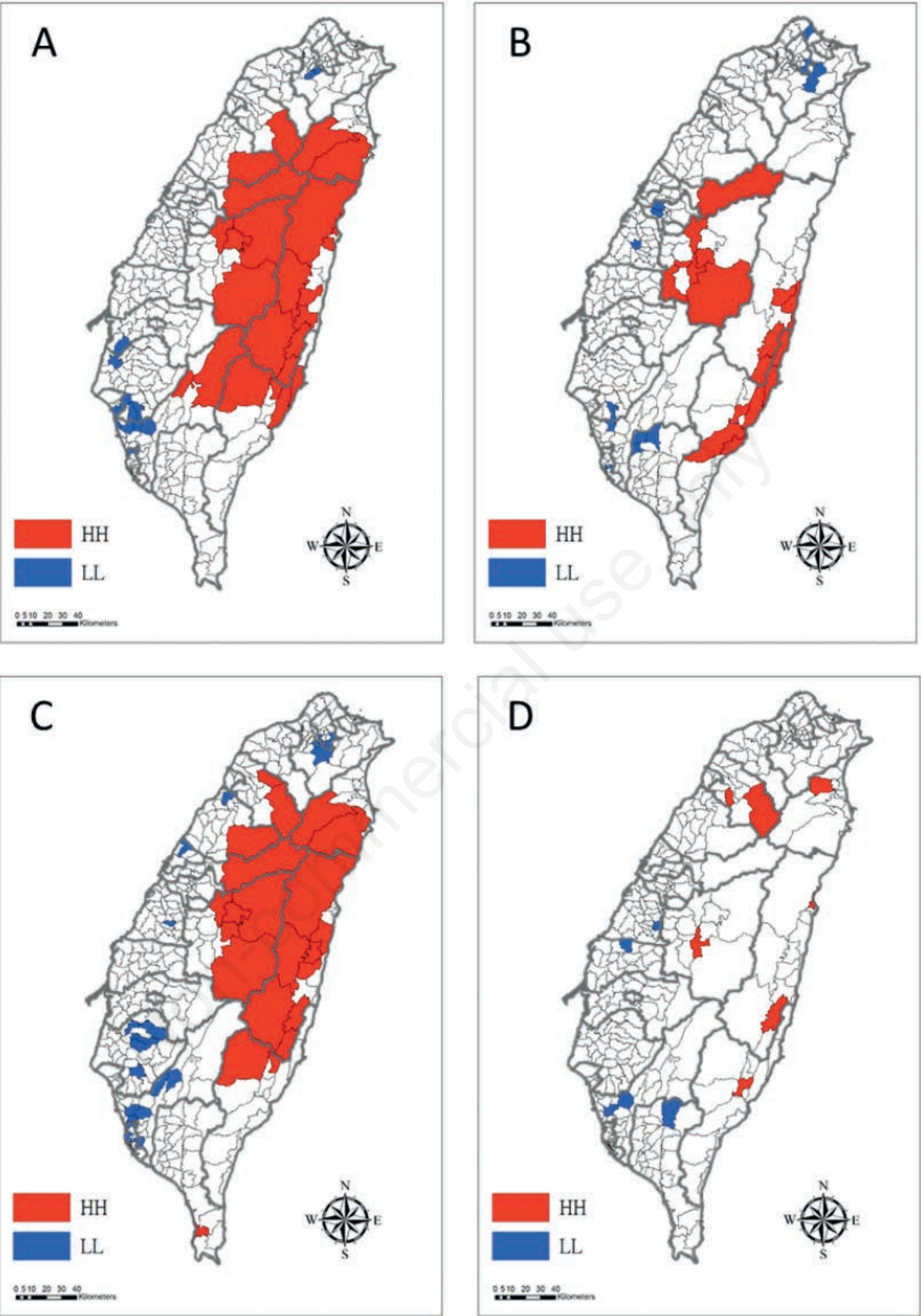

Figure 2. Cluster graph of childhood deaths due to unintentional injury by age and gender in 2000-2007. (A) Results for males 0-4 years of age; (B) Results for females 0-4 years of age; (C) Results for males 5-9 years of age; (D) Results for females 5-9 years of age. HH, high rates; LL, low rates. 
0.157 indicating statistical significance and the $\mathrm{R}^{2}$ ranged from 0.159 to 0.182 . Although these deaths were influenced by spatial clustering, the effect was small. All four SES components were significantly related to death due to drowning (Tables 3 and 4). The most significant factor was poverty (beta coefficient $=0.397$ ). Moran's $I$ of the residuals was $0.1607(\mathrm{P} \leq 0.01)$ and the spatial lag model showed Rho to be 0.332 indicating statistical significance $(\mathrm{P} \leq 0.01)$, while $\mathrm{R}^{2}$ ranged from 0.233 to 0.304 indicating that these deaths were influenced by spatial and neighbouring effects For death due to suffocation, poverty rate and family fragility were the significant factors (Table 2). Moran's $I$ of the residual value was $0.1041(\mathrm{P} \leq 0.01)$ and the spatial lag model showed Rho level as 0.186 indicating statistical significance $(\mathrm{P} \leq 0.01)$, while $\mathrm{R}^{2}$ ranged from 0.047 to 0.076 . Although these deaths were influenced by spatial effects, the effect was small.

\section{Discussion}

The study highlights the relationship between different arealevel socioeconomic indicators and unintentional injury mortality rates in Taiwan. These rates appeared to be significantly modified by sociodemographic factors. We found that drowning was more common near the east coast than anywhere else, while deaths due to traffic were common in the central mountainous area. The study showed that local socioeconomic environments influence the mechanism that can leads to injury-related deaths. Additionally, regional clusters in central and eastern Taiwan were noted in the lowest age groups (0-4-years old), significantly so in males. Children living in deprived areas under disorganized family conditions constitute vulnerable subgroups whose needs should be con- sidered in future policies. Immediate attention is called for.

Death due to unintentional injury is often influenced by place of residence and parental occupation. Using linear regression analysis, Durkin et al. (1994) report that childhood unintentional injury in northern Manhattan NY, USA from 1983 to 1991 is significantly related to family income, single parent household and male unemployment. In addition, incomplete family structure, such as households headed by grandparents is also an important factor (Bishai et al., 2008). Children living in rural areas show a higher mortality rate than those living in townships or cities and this effect lasts until the child reaches 15 years of age (Hu et al., 2010). Analysing socioeconomic parameters, Nolasco et al. (2009) found that unemployment and low education are associated with higher traffic accidents in adolescents. In South Korea, a cohort study concluded that deaths due to unintentional injury in children $<8$ years old is associated with life in rural areas, parents with a low level of education and parental occupation (Hong et al., 2010). In concurrence, our study found socioeconomic components, including poverty, economic burdens and fragility as well as unemployment, to be significantly associated with children's deaths due to unintentional injury

Flower et al. (2006) conducted an analysis of agricultural areas in the US, including Iowa and North Carolina from 1973 to 1998 reporting that although the overall mortality rate did not increase, the number of deaths related to agricultural machines had increased (odds ratio $=3.93$ ). Their study suggests that different area-level socioeconomic components should be taken into account even though overall mortality remained stable. It highlights the importance of the geographical environment as the possible determinants of mortality due to unintentional injury.

This study has some limitations, e.g., the number of partici-
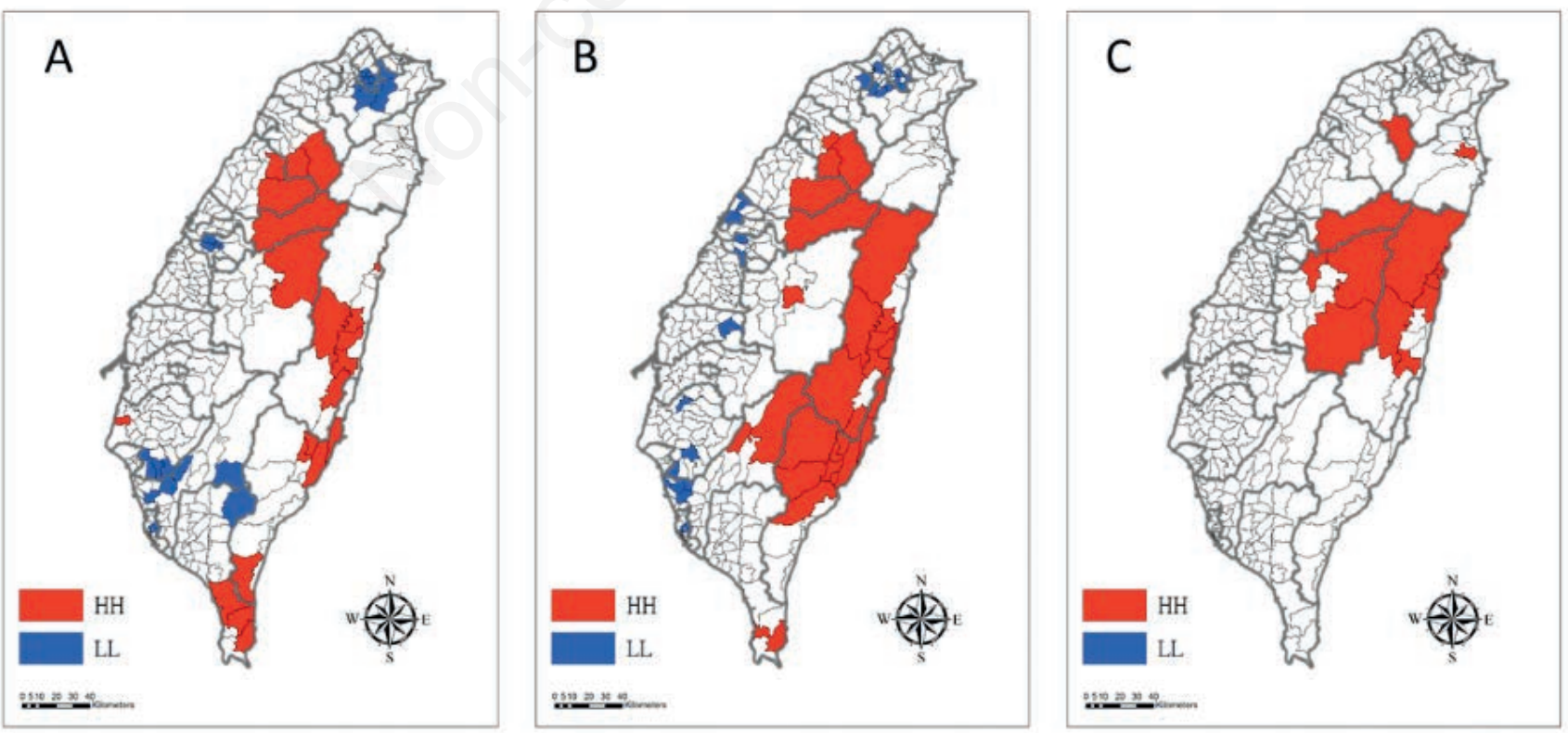

Figure 3. Cluster graph of childhood unintentional injury death by type 2000-2007. (A) Traffic accidents; (B) Drowning; (C) Suffocation. $\mathrm{HH}$, high rates; LL, low rates. 

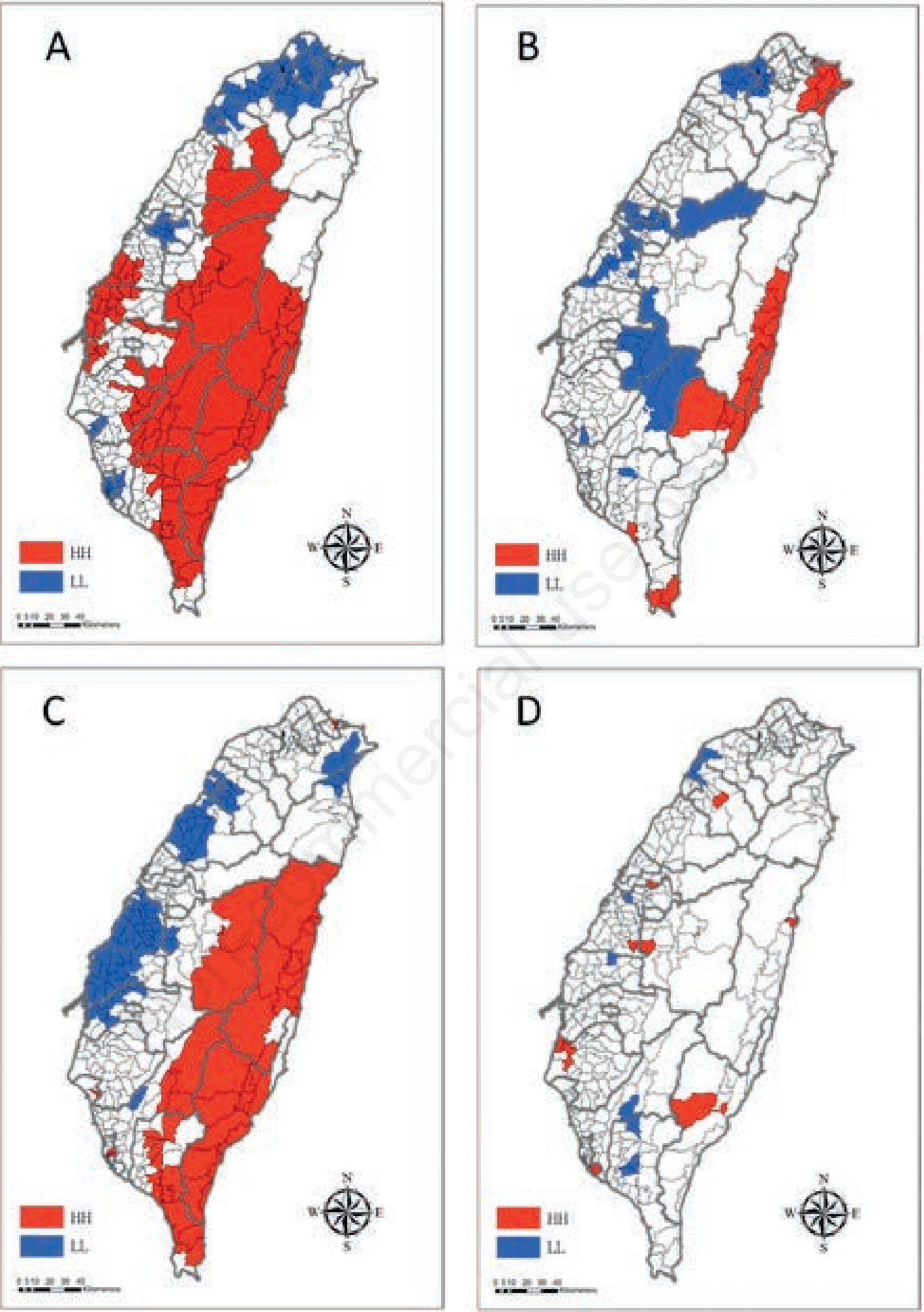

Figure 4. The clustering of four socioeconomic concepts using LISA analysis. (A) With regard to the poverty component, 92 high rates $(\mathrm{HH})$ regions and $85 \mathrm{low}$ rates (LL) regions were identified; (B) With regard to the family burden component, $26 \mathrm{HH}$ regions and 48 LL regions were identified; (C) With regard to the family fragility component, $52 \mathrm{HH}$ regions and $72 \mathrm{LL}$ regions were identified; (D) With regard to the unemployment component, $11 \mathrm{HH}$ regions and $9 \mathrm{LL}$ regions were identified. 
Table 3. Regression analysis of childhood deaths due to drowning and suffocation 2000-2007.

\begin{tabular}{|c|c|c|c|c|}
\hline \multirow[b]{2}{*}{ Variable } & \multicolumn{2}{|c|}{ Ordinary Least Square model } & \multicolumn{2}{|c|}{ Spatial lag model } \\
\hline & Coefficient & SE & Coefficient & SE \\
\hline \multicolumn{5}{|c|}{ Drowning } \\
\hline Regional poverty & $0.397^{* * *}$ & 0.046 & $0.289 * * *$ & 0.050 \\
\hline Family burden & $0.169 * * *$ & 0.046 & $0.100^{* *}$ & 0.045 \\
\hline Family fragility & $0.214^{* * *}$ & 0.046 & $0.160 * * *$ & 0.046 \\
\hline Regional unemployment & $0.094^{* *}$ & 0.046 & 0.086 & 0.044 \\
\hline Rho $(\rho)$ level & & & $0.332 * * *$ & \\
\hline Adjusted $\mathrm{R}^{2}$ & 0.233 & & 0.304 & \\
\hline Akaike information criterion & 902.685 & & 882.803 & \\
\hline Schwarz criterion & 921.961 & & 905.934 & \\
\hline Residual value of Moran's I & $0.1607^{* *}$ & & & \\
\hline \multicolumn{5}{|c|}{ Suffocation } \\
\hline Regional poverty & $0.197^{* * *}$ & 0.052 & $0.177^{* * *}$ & 0.053 \\
\hline Family burden & 0.050 & 0.052 & 0.035 & 0.051 \\
\hline Family fragility & $0.116^{*}$ & 0.052 & $0.106 * *$ & 0.051 \\
\hline Regional unemployment & 0.030 & 0.052 & 0.027 & 0.051 \\
\hline Rho $(\rho)$ level & & & $0.186^{* *}$ & \\
\hline Adjusted $\mathrm{R}^{2}$ & 0.047 & & 0.076 & \\
\hline Akaike information criterion & 979.437 & & 972.444 & \\
\hline Schwarz criterion & 998.713 & & 987.864 & \\
\hline Residual value of Moran's I & $0.1041^{*}$ & 2 & & \\
\hline
\end{tabular}

Table 4. Regression analysis of total childhood deaths due to unintentional injury and those due to traffic accidents 2000-2007.

\begin{tabular}{|c|c|c|c|c|}
\hline \multirow[b]{2}{*}{ Variable } & \multicolumn{2}{|c|}{ Ordinary Least Square model } & \multicolumn{2}{|c|}{ Spatial lag model } \\
\hline & Coefficient & SE & Coefficient & SE \\
\hline \multicolumn{5}{|c|}{ All types of injury } \\
\hline Regional poverty & $0.419 * * *$ & 0.045 & $0.302 * * *$ & 0.048 \\
\hline Family burden & $0.188^{* * *}$ & 0.045 & $0.104^{* *}$ & 0.043 \\
\hline Family fragility & $0.230 * * *$ & 0.045 & $0.171^{* * *}$ & 0.044 \\
\hline Regional unemployment & $0.171^{* * *}$ & 0.045 & $0.156^{* * *}$ & 0.042 \\
\hline Rho $(\rho)$ level & & & $0.377^{* * *}$ & \\
\hline Adjusted $\mathrm{R}^{2}$ & 0.285 & & 0.375 & \\
\hline Akaike information criterion & 878.426 & & 847.372 & \\
\hline Schwarz criterion & 897.701 & & 870.502 & \\
\hline Residual value of Moran's I & $0.2304^{* *}$ & & & \\
\hline \multicolumn{5}{|c|}{ Traffic injury } \\
\hline Regional poverty & $0.360 * * *$ & 0.049 & $0.318^{* * *}$ & 0.053 \\
\hline Family burden & 0.082 & 0.049 & 0.052 & 0.048 \\
\hline Family fragility & $0.157^{* * *}$ & 0.049 & $0.140 * * *$ & 0.049 \\
\hline Regional unemployment & 0.088 & 0.049 & 0.082 & 0.048 \\
\hline Rho $(\rho)$ level & & & $0.157^{* *}$ & \\
\hline Adjusted $R^{2}$ & 0.159 & & 0.182 & \\
\hline Akaike information criterion & 934.753 & & 931.81 & \\
\hline Schwarz criterion & 954.029 & & 948.23 & \\
\hline Residual value of Moran's I & $0.0917 *$ & & & \\
\hline
\end{tabular}

$\mathrm{SE}$, standard error; ${ }^{*}$-value $<0.05 ; *$ P-value $<0.01 ; * *$ P-value $\leq 0.001$. 
pants and structure were different between the years investigated, and therefore the distribution childhood deaths due to unintentional injury also varied (Appendix Figure A1). We tried to provide a thorough trend of the spatial cluster analysis by using accumulative data on and performing a spatial lag regression evaluation. Although the population structure changed over time, up to $94.6 \%$ of those in residence stayed in the same county and township according to the health insurance database and population dynamics survey file. Indeed, the limitation on the precise person-level information could be eliminated (Lin et al., 2011) by relying on area-level analysis. In addition, we could not cover all socioeconomic variables. For example, although parental age and foreign parents were not included in our study, multiple socioeconomic factors were considered. Nine socioeconomic variables were settled into four major components with $83.24 \%$ variability using the Kaiser-Meyer-Olkin measure. Nevertheless, other social factors, such as social atmosphere and culture, cannot be quantified. We used both step-by-step regression and spatial lag models to evaluate the association between socioeconomic disadvantages and deaths due to unintentional injury. Furthermore, the hotspots were identified to increase public awareness regarding the parts of the country needing more economic and social support to avoid preventable deaths.

\section{Conclusions}

Unintentional injury is a major cause of death in children in Taiwan and elsewhere. This study provides evidence by further examining the association between socioeconomic factors and deaths based on spatial, neighbouring effects. Significant associations were found between death due to unintentional injury and social disadvantages including local poverty situations, family fragility, family burden and unemployment while controlling for spatial autocorrelation. The results presented here can be used to target and improve neighbourhoods with geographic inequalities that have led to high child mortality due to unintentional injury.

\section{References}

Ahmad OB, Boschi-Pinto C, Lopez AD, Murray CJ, Lozano R, Inoue M, 2001. Age standardization of rates: a new WHO standard. World Health Organization, Geneva, Switzerland, pp 910.

Baker SP, Whitfield RA, O’Neill B, 1987. Geographic variations in mortality from motor vehicle crashes. N Engl J Med 316:1384-7.

Bishai D, Trevitt JL, Zhang Y, McKenzie LB, Leventhal T, Gielen AC, Guyer B, 2008. Risk factors for unintentional injuries in children: are grandparents protective? Pediatrics 122:e980-7.

Blakely T, Atkinson J, Kiro C, Blaiklock A, D’Souza A, 2003. Child mortality, socioeconomic position, and one-parent families: independent associations and variation by age and cause of death. Int J Epidemiol 32:410-8.

Brunsdon C, Fotheringham S, Charlton M, 1998. Geographically weighted regression. J Royal Statist Soc: Series D (The Statistician) 47:431-43.

Centers for Disease Control and Prevention (CDC), USA, 2013. Available from: https://www.cdc.gov/nchs/icd/icd $9 \mathrm{~cm} . h t m$
Accessed: November 23, 2018.

Centers for Disease Control and Prevention (CDC), USA, 2011. Matrix of E-code Groupings. Avaliable from https://www.cdc.gov/injury/wisqars/ecode_matrix.html. Accessed: November 23, 2018.

Cerny BA, Kaiser HF, 1977. A study of a measure of sampling adequacy for factor-analytic correlation matrices. Multivar Behav Res 12:43-7.

Cheng TL, Dreyer BP, Jenkins RR, 2009. Introduction: Child health disparities and health literacy. Pediatrics 124:S161-2.

Clayton D, Kaldor J, 1987. Empirical Bayesian estimates of agestandardized relative risks for use in disease mapping. Biometrics 43:671-82.

Cubbin C, LeClere F, Smith G, 2000. Socioeconomic status and injury mortality: individual and neighbourhood determinants. J Epidemiol Commun Health 54:517-24.

Donroe J, Tincopa M, Gilman RH, Brugge D, Moore DA, 2008. Pedestrian road traffic injuries in urban Peruvian children and adolescents: case control analyses of personal and environmental risk factors. PLoS One 3:e3166.

Durkin MS, Davidson LL, Kuhn L, O’Connor P, Barlow B, 1994. Low-income neighborhoods and the risk of severe pediatric injury: a small-area analysis in northern Manhattan. Am J Public Health 84:587-92.

Flower KB, Hoppin JA, Shore DL, Lynch CF, Blair A, Knott C, Alavanja MC, Sandler DP, 2006. Causes of mortality and risk factors for injury mortality among children in the agricultural health study. J Agromed 11:47-59.

Hong J, Lee B, Ha EH, Park H, 2010. Parental socioeconomic status and unintentional injury deaths in early childhood: consideration of injury mechanisms, age at death, and gender. Accid Anal Prev 42:313-9.

Hu G, Baker SP, Baker TD, 2010. Urban-rural disparities in injury mortality in China, 2006. J Rural Health 26:73-7.

Jin A, Brussoni M, George MA, Lalonde CE, McCormick R, 2017. Risk of hospitalization due to unintentional fall injury in British Columbia, Canada, 1999-2008: Ecological associations with socioeconomic status, geographic place, and aboriginal ethnicity. J Racial Ethnic Health Dispar 4:558-70.

Laing GJ, Logan S, 1999. Patterns of unintentional injury in childhood and their relation to socio-economic factors. Public Health 113:291-4.

Liang FW, Huang YL, Wu MH, Lue HC, Chiang TL, Lu TH, 2016. Child mortality: Taiwan compared with OECD countries. Taiwan Gong Gong Wei Sheng Za Zhi 35:221.

Lin M, Yang A, Wen T, 2011. Using regional differences and demographic characteristics to evaluate the principles of estimation of the residence of the population in National Health Insurance Research Databases (NHIRD). Taiwan J Public Health 30:347-61.

Ministry of Health and Welfare, Taiwan, 2016. Health Statistics II. Vital Statistics. Ministry of Health, Taiwan.

Ministry of Health and Welfare, Taiwan, 2018. Cause of Death Statistics. Available from https://www.mohw.gov.tw/np-1282.html Accessed: November, 23, 2018.

Nolasco A, I. Melchor I, Pina JA, Pereyra-Zamora P, Moncho J, Tamayo N, Garcia-Senchermes C, Zurriaga O, MartinezBeneito MA, 2009. Preventable avoidable mortality: evolution of socioeconomic inequalities in urban areas in Spain, 19962003. Health Place 15:702-11.

Östberg V, 1997. The social patterning of child mortality: the 
importance of social class, gender, family structure, immigrant status and population density. Sociol Health Illn 19:415-35.

Pearson K, 1901. LIII. On lines and planes of closest fit to systems of points in space. London Edinburgh Dublin Philos Mag J Sci 2:559-72.

Poulton R, Caspi A, Milne BJ, Thomson WM, Taylor A, Sears MR, Moffitt TE, 2002. Association between children's experience of socioeconomic disadvantage and adult health: a life-course study. Lancet 360:1640-5.

Roberts I, Norton R, Jackson R, Dunn R, Hassall I, 1995. Effect of environmental factors on risk of injury of child pedestrians by motor vehicles: a case-control study. BMJ 310:91-4.

Roberts I, Power C, 1996. Does the decline in child injury mortality vary by social class? A comparison of class specific mortality in 1981 and 1991. BMJ 313:784-6.

Schnitzer PG, Ewigman BG, 2008. Household composition and fatal unintentional injuries related to child maltreatment. J
Nurs Scholarsh 40:91-7.

Scholer SJ, Hickson GB, Ray WA, 1999. Sociodemographic factors identify US infants at high risk of injury mortality. Pediatrics 103:1183-8.

Singh GK, Kogan MD, 2007. Widening socioeconomic disparities in US childhood mortality, 1969 2000. Am J Public Health 97:1658-65.

Singh GK, Yu SM, 1996. US childhood mortality, 1950 through 1993: Trends and socioeconomic differentials. Am J Public Health 86:505-12.

WHO, 2016. Global Health Estimates 2015: Deaths by cause, age, sex, by country and by region, 2000-2015. World Health Organization, Geneva, Switzerland. Available from: http://ghdx.healthdata. org/gbd-2016

Yang CY, Chiu JF, Lin MC, Cheng MF, 1997. Geographic variations in mortality from motor vehicle crashes in Taiwan. J Trauma 43:74-7. 